\title{
Contaminação ambiental por ovos e larvas de helmintos em fezes de cães na área central do Balneário Cassino, Rio Grande do Sul
}

\author{
Environmental contamination by helminth eggs and larvae in dog feces \\ from central area of Cassino Beach, Rio Grande do Sul
}

\author{
Carlos James Scaini', Ricardo Navarrete de Toledo², Raquel Lovatel'², Maria Alix Dionello', \\ Fabiane dos Anjos Gatti' ${ }^{1}$, Lulie Susin ${ }^{1}$ e Vera Regina Mendonça Signorini ${ }^{1}$
}

\begin{abstract}
Resumo Para investigar a presença de helmintos, agentes de zoonoses parasitárias, foram examinadas 237 amostras fecais de cães, na área central do principal balneário do litoral sul do Rio Grande do Sul. As principais contaminações foram: ovos e larvas do gênero Ancylostoma (71,3\%), ovos de Trichuris (32,5\%) e Toxocara (9,3\%).
\end{abstract}

Palavras-chaves: Fontes de contaminação do solo. Helmintos. Zoonoses.

Abstract In order to investigate the presence of helminthes agents of parasitic zoonoses, were examined 237 fecal samples of dogs from central area of the main beach of south coast of Rio Grande do Sul State. The eggs and larvae of genus Ancylostoma (71.3\%) and Trichuris (32.5\%) and Toxocara eggs (9.3\%) were the most prevalent parasites detected.

Key-words: Soil pollutants. Helminths. Zoonoses.

Os cães desempenham o papel de hospedeiro definitivo para algumas espécies de helmintos, que podem causar enfermidades importantes para o homem. O crescente número de cães domiciliados, peridomiciliados e errantes, de modo geral, em todo o Brasil, associado ao fácil acesso destes animais a locais de lazer, aumenta o risco de infecção, especialmente para as crianças. Dentre as espécies de helmintos com potencial zoonótico, encontram-se os agentes etiológicos da larva migrans visceral $(\mathrm{LMV})^{112}$, larva migrans cutânea $(\mathrm{LMC})^{10}$, enterite eosinofílica ${ }^{1}$, tricurose ${ }^{69}$ e hidatidose ${ }^{7}$.

No principal balneário do litoral sul do Rio Grande do Sul, o Balneário Cassino, existem as condições epidemiológicas necessárias para a existência de doenças parasitárias transmitidas pelos cães, tais como condições climáticas favoráveis para a fase de vida livre dos parasitos e um grande número destes animais, com livre trânsito em áreas de recreação infantil, nas vias de passeio para pedestres e na areia da praia. O presente trabalho teve como objetivo investigar a contaminação ambiental por ovos e larvas de helmintos, com potencial zoonótico, em fezes de cães na área central deste balneário.

No período de março a novembro de 2002, foram colhidas 237 amostras de fezes de cães, na avenida principal e em duas ruas imediatamente paralelas, no Balneário Cassino, município de Rio Grande, RS. Nesta área, estão situadas duas praças de recreação infantil e uma via para pedestres no centro da avenida. Somente amostras de fezes não ressecadas foram colhidas. As amostras foram conservadas a $4^{\circ} \mathrm{C}$ e examinadas através do método de flutuação de Willis ${ }^{12}$ com algumas modificações, sendo utilizada a solução saturada de cloreto de sódio (densidade 1, 200).

Das 237 amostras, 86,1\% apresentaram positividade para ovos e/ou larvas de helmintos (contaminação simples $66,7 \%$ e contaminação mista $33,3 \%$ ). Os resultados referentes à freqüência dos

\footnotetext{
1. Setor de Parasitologia do Departamento de Patologia da Fundação Universidade Federal do Rio Grande, Rio Grande, RS. 2. Curso de Medicina da Fundação Universidade Federal do Rio Grande, Rio Grande, RS.

Endereço para correspondência: Dr. Carlos James Scaini. Rua General Osório s/n, Centro, 96200-400 Rio Grande, RS, Brasil.

Tel: 5553 233-8895, Fax: 5553 231-3803

e-mail:dpacjs@furg.br

Recebido para publicação em 9/6/2003

Aceito em 6/8/2003
} 
helmintos detectados podem ser observados na Figura 1. A principal contaminação registrada foi por Ancylostoma spp, em $71,3 \%$ (169) das amostras, sendo que destas, $11,8 \%$ (20) já apresentavam larvas rabditóides e filarióides.

Ovos de Ancylostoma spp, Trichuris spp e Toxocara spp foram identificados isoladamente em 43,5\% (103), $9,7 \%$ (23) e $3 \%$ (7) das amostras, respectivamente. A principal associação verificada foi com Ancylostoma spp e Trichuris spp (16,9\%). Também foram observadas associações com Ancylostoma spp, Trichuris spp e Toxocara spp (2,1\%), e com Ancylostoma spp e Toxocara $\operatorname{spp}(2,1 \%)$. Outras associações foram observadas, porém em menor freqüência.
O parasita que apresentou maior freqüência foi do gênero Ancylostoma, o que era esperado, pois este é facilmente encontrado parasitando cães e gatos da região. Em outros trabalhos, este gênero já foi apontado como o mais prevalente ${ }^{58}$. É importante ressaltar, que $11,8 \%$ das amostras positivas para Ancylostoma, já apresentavam larvas rabditóides e filarióides, demonstrando que o ambiente estudado era adequado para o embrionamento, desenvolvimento e sobrevivência das larvas, o que indica a existência de condições favoráveis à infecção humana. Dentre os agentes etiológicos da LMC, o principal é a espécie $A$. braziliense ${ }^{11}$.

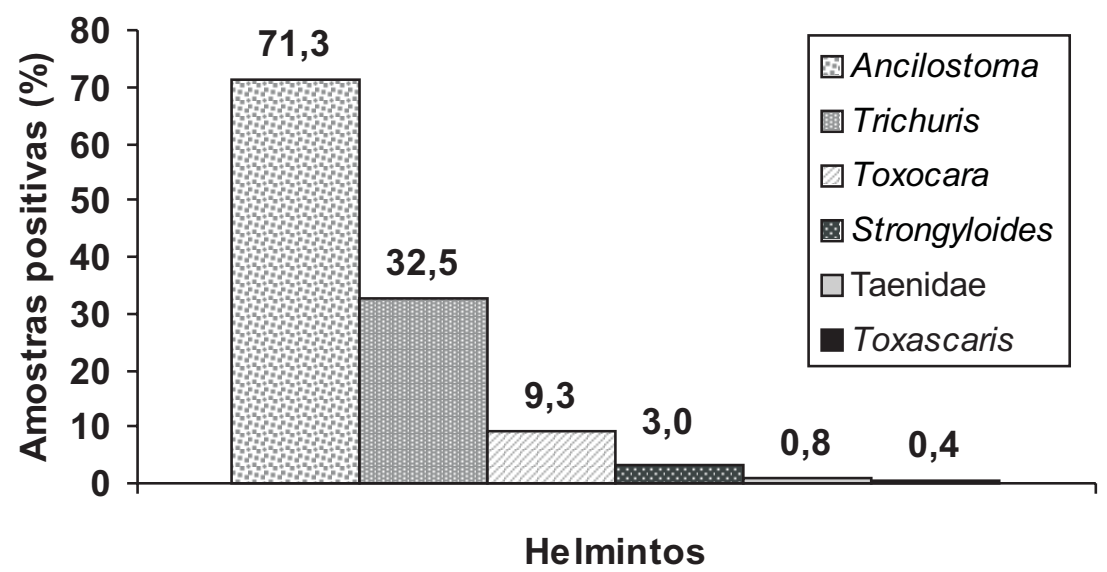

Figura 1 - Freqüência de helmintos em amostras de fezes de cães da área central do Balneário do Cassino, Rio Grande, RS.

O segundo gênero mais detectado foi Trichuris, sendo já registrada infecção entérica no homem causada por T. vulpis, parasito de cães ${ }^{6}$, e o terceiro gênero mais freqüente $(9,3 \%)$ foi Toxocara, principal causa da LMV. A freqüência deste parasita foi aquém do esperado, talvez porque a maioria dos animais que tiveram suas fezes examinadas era adulta, contrastando com resultados de alguns trabalhos que mostraram positividade superior para ovos deste parasito $(41,7 \% \text { e } 100 \%)^{43}$. Além destes, foram detectados ovos de Taenidae, ovos e larvas de
Strongyloides sp. A principal infecção mista encontrada também envolveu Ancylostoma spp e Trichuris spp, os dois gêneros que apresentaram as maiores freqüências isoladas.

Estes resultados demonstram que os cães desempenham um importante papel como fonte de contaminação ambiental de parasitos com potencial zoonótico, necessitando maior atenção da população em relação à saúde destes animais, visando a diminuição do risco de infecção para o homem e aos próprios animais.

\section{REFERÊNCIAS BIBLIOGRÁFICAS}

1 Bahgat MA, Gindy EI, Mahamoud LA, Hegab MH, Shahin AM. Evaluation of the role of Ancylostoma caninum in humans as a cause of acute and recurrent abdominal pain. Journal of the Egyptian Society of Parasitology 29:873-882, 1999.

2 Beer SA, Novosil'tsev GI, Mel'nikova LI. The role of the water factor in the dissemination of Toxocara eggs and spread toxocariasis in a megalopolis. Parazitologiia 33:129-135, 1999.

3 Chieffi PP, Müller EE. Estudo da variação mensal na contaminação do solo por ovos de Toxocara sp (Nematoda, Ascaroidea) na zona urbana do município de Londrina, Estado do Paraná, Brasil. Revista do Instituto Adolfo Lutz 38:13-16, 1978.

4 Ferreira LF, Oliveira EL, Camillo-Coura L. Sobre a presença de ovos de Toxocara, em praças da cidade do Rio de janeiro. Revista da Sociedade Brasileira de Medicina Tropical 10:5153, 1976.

5 Gennari SM, Kasai N, Pena HFJ, Cortez A. Ocorrência de protozoários e helmintos em amostras de fezes de cães da cidade de São Paulo. Brazilian Journal of Veterinary Research and Animal Science 36:87-91, 1999. 
6 Hall JE, Sonnenberg B. An apparent case of human infection with the whipworms of dogs, Trichuris vulpis (Froelich, 1789). Journal of Parasitology 42:197-199, 1956.

7 Hernando E, Garcia Calleja JL, Cordoba E, Lahuerta L, del Rio F, Ferreira V. Hepatic hydatidosis. Review of a series of 677 surgically treated patients. Gastroenterologia y Hepatologia. 19:140-145, 1996.

8 Hoffmann AN, Beltrão N, Botton SA, Caminha BX, de la Rue $\mathrm{ML}$. Intestinal nematodes of stray dogs as zoonoses agents in D. Pedrito city (RS-Brazil). Boletim Chileno de Parasitologia 55:92-93, 2000.
9 Mirdha BR, Singh YG,Samantray, JC, Mishra B. Trichuris vulpis infection in slum children. Indian Journal of Gastroenterology 17:154, 1998.

10 Nunes CM, Pena FC, Negrelli, GB, Anjo CGS, Nakano MM, Stobbe, NS. Ocorrência de larva migrans na areia de áreas de lazer das escolas municipais de ensino infantil, Araçatuba, SP, Brasil. Revista de Saúde Pública 34:656-658, 2000.

11 Schantz PM. Parasitic zoonosis in perspective. International Journal for Parasitology 21:161-170, 1991.

12 Willis $\mathrm{HH}$. A simple levitation method for the detection of hookworm ova. The Medical Journal Australia 8:375-376, 1921. 